\title{
Atividade antimicrobiana e potencial terapêutico do gênero Lippia sensu lato (Verbenaceae)
}

\author{
Patrícia Silva Costa ${ }^{1,4}$, Elnatan Bezerra de Souza ${ }^{2}$, Erika Helena Salles de Brito ${ }^{3}$ e \\ Raquel Oliveira dos Santos Fontenelle ${ }^{1,2}$
}

Recebido: 7.8.2016; aceito: 3.04.2017

\begin{abstract}
Antimicrobial activity and therapeutic potential of the genus Lippia sensu lato (Verbenaceae)). The growing number of infectious diseases combined with the continuous increase of antimicrobial resistance of certain microorganisms justify the constant search for new drugs. Given this situation, plants are a rich source of bioactive resources of pharmacological interest. The Verbenaceae family, especially the genus Lippia L., has representatives with potential already confirmed against various pathogens; the species of Lippia are widely used in folk medicine for their anti-inflammatory, antifungal, antiseptic, anti-hypertensive, anxiolytic, anti-leishmania, antiviral, and digestive properties, among other applications. This review gathers information about the antimicrobial potential of the main species of the genus Lippia, relating to the type of extract, its constituents, and the importance of this genus in the investigation of natural products and their phytochemical and biological characteristics.
\end{abstract}

Keywords: antibiotics, antifungals, phytochemical composition, natural products, tribe Lantaneae

RESUMO - (Atividade antimicrobiana e potencial terapêutico do gênero Lippia sensu lato (Verbenaceae). O crescente número de doenças infecciosas somado ao aumento contínuo da resistência antimicrobiana de determinados micro-organismos justificam a busca constante por novos fármacos. Diante dessa situação, os vegetais representam uma fonte rica de recursos bioativos de interesse farmacológico, dentre os quais a família Verbenaceae, que possui representantes com potencial já confirmados contra diversos agentes patogênicos, especialmente o gênero Lippia L., cujas espécies são muito utilizadas na medicina popular por possuírem propriedades anti-inflamatória, antifúngica, antisséptica, anti-hipertensiva, ansiolítica, anti-leishmania, antiviral, digestivas, entre outras aplicações. A presente revisão reúne informações acerca do potencial antimicrobiano das principais espécies do gênero Lippia, relacionando ao tipo de extrato, seus constituintes e a importância desse gênero dentro da prospecção de produtos naturais, bem como suas características fitoquímicas e biológicas.

Palavras-chave: antibióticos, antifúngicos, composição fitoquímica, produtos naturais, tribo Lantaneae

\section{Introdução}

Verbenaceae compreende cerca de 36 gêneros e 1.000 espécies com distribuição pantropical (Souza \& Lorenzi 2012). Na região neotropical ocorrem 32 gêneros e 480 espécies, sendo o Brasil o país que apresenta a maior riqueza de táxons de Verbenaceae com 16 gêneros e 290 espécies, das quais 191 são endêmicas, a maioria das quais distribuídas principalmente na Cadeia do Espinhaço e no Planalto
Central (Goulart \& Marcati 2008, Salimena 2000, Soares \& Tavares-Dias 2013, Salimena \& Múlgura 2015).

As Verbenaceae são plantas que se apresentam sob a forma de ervas, arbustos, subarbustos ou lianas. No Brasil, os gêneros mais representativos em diversidade específica são: Lippia L. (88) Stachytarpheta Vahl (81), Glandularia J.F. Gmel. (31), Lantana L. (22), Verbena L. (16) e Citharexylum Mill. (13) (Gomes et al. 2011, Salimena \& Múlgura 2015, Salimena et al. 2015).

1. Universidade Estadual do Ceará, Centro de Ciências e Tecnologia, Programa de Pós-graduação em Recursos Naturais, Avenida Dr. Silas Muguba, 1.700, Itaperi, 60740-000 Fortaleza, CE, Brasil

2. Universidade Estadual Vale do Acaraú, Centro de Ciências Agrárias e Biológicas, Curso de Ciências Biológicas, Av. da Universidade, 850, Betânia, 62040-370 Sobral, CE, Brasil

3. Universidade da Integração Internacional da Lusofonia Afro-Brasileira, Curso de Enfermagem, Campus Palmares, Rodovia CE 060, Km 51, Acarape, 49900-000 Ceará, Brasil

4. Autor para correspondência: patriciasilva10@hotmail.com 
Dentre os gêneros de Verbenaceae que se destacam pelo potencial fitoquímico e pelo seu uso medicinal estão Lippia e Lantana (Pinto et al. 2006), com cerca de 120 e 100 espécies respectivamente. Ambos pertencem à tribo Lantaneae, onde se incluem nove gêneros e 275 espécies. Juntos, esses dois gêneros correspondem a aproximadamente $80 \%$ dos representantes desta tribo (Marx et al. 2010). Do ponto de vista fitoquímico, Lantaneae é o grupo mais importante de Verbenaceae, pois é somente nele que se enquadram as espécies produtoras de óleos essenciais (Atkins 2004).

Lippia é considerado um dos principais gêneros da família Verbenaceae, com aproximadamente 200 espécies de ervas, arbustos e pequenas árvores, cujos maiores centros de dispersão se encontram nos países do Hemisfério Sul e em algumas regiões tropicais da América do Norte e Austrália (Reis et al. 2014, Gomes et al. 2011, Sena Filho et al. 2006, Silva et al . 2006, Pascual et al. 2001). No campo, esse gênero se destaca por sua aparência chamativa no período de floração e por seu aroma forte e geralmente agradável, característico de seu óleo essencial (Oliveira et al. 2006).

$\mathrm{Na}$ indústria alimentícia, algumas espécies como Lippia alba L., são utilizadas como conservantes naturais (Machado et al. 2011), podendo ainda eliminar células microbianas viáveis em superfícies de alimentos sólidos como carne, além de ser útil para higienização de bancadas, equipamentos e utensílios (Pereira et al. 2008).

Diante da notória importância terapêutica e científica do gênero Lippia L., este artigo teve como objetivo fazer um levantamento bibliográfico sobre o potencial antimicrobiano das principais espécies do gênero, expondo de forma geral, os estudos etnofarmacológicos, bem como a utilização popular e seu potencial antimicrobiano, além das partes vegetais mais utilizadas, seus extratos e constituintes, apresentados na tabela 1 .

\section{Material e métodos}

Este trabalho trata-se de uma sumarização de pesquisas baseadas na utilização popular de espécies pertencentes ao gênero Lippia e suas atividades comprovadas em testes in vitro. Para o levantamento de dados, buscou-se por artigos científicos que atribuíam atividade antimicrobiana às espécies desse gênero, focando no seu potencial antibacteriano e antifúngico. Tal levantamento ocorreu entre setembro de 2015 e março de 2016, compreendendo o período de 1989 a 2015, usando como termo indexador para a pesquisa "Lippia antimicrobial activity" e "Medicinal use of the genus Lippia".

Visando assegurar e ampliar a abrangência desta revisão, foram consultadas as seguintes bases: Academia.edu (https://www.academia.edu), Google Scholar (http://www.scholar.google.com), Science Direct (http://www.sciencedirect.com) e Scielo (http:// www.scielo.org). Durante as buscas, foram excluídos diversos tipos de trabalhos, tais como artigos não indexados, teses, dissertações e resenhas, pois os mesmos poderiam não ter passado por um processo de avaliação pelos pares.

\section{Resultados e Discussão}

Potencial antimicrobiano do gênero Lippia - São muitas as referências sobre o valor clínico dos constituintes encontrados em representantes de Verbenaceae (Blank et al. 2015, Guimarães et al. 2014, Gomes et al. 2011, López et al. 2011). No Brasil, essas espécies possuem uma larga importância na medicina popular. Muitas comunidades, especialmente indígenas e rurais, usam esses vegetais em forma de chás, infusões, decocções, xaropes, banhos, elixir, gargarejo ou bochecho, inalação, tintura, suco ou sumo (Santos et al. 2015, Maciel et al. 2002). A partir do conhecimento etno-cultural, muitos estudos são impulsionados, fazendo com que sejam confirmadas, cientificamente, as propriedades bioativas relatadas pelos adeptos da medicina popular.

Por possuir atividade comprovada frente um grande número de doenças, espécies representantes desse gênero estão presentes em algumas unidades de saúde da família, no interior do estado do Ceará, sendo empregadas como fitoterápicos alternativos aos medicamentos convencionais, por serem mais acessíveis a pacientes oriundos de zonas rurais ou ainda que não têm condições de adquirir tais medicamentos comercialmente. Esses fitoterápicos são cedidos aos pacientes em forma de antissépticos bucais, tinturas, cremes e elixir (Silva et al. 2006).

Dentre os vários produtos extraídos a partir desses vegetais, os mais citados em artigos científicos são os constituintes voláteis ou óleos essenciais e extratos alcoólicos, sendo os mais comuns etanol, metanol e acetato de etila das partes aéreas das amostras botânicas, principalmente as folhas (secas ou frescas), muito embora a raiz também seja citada esporadicamente (Oliveira et al. 2014, Santos et al. 


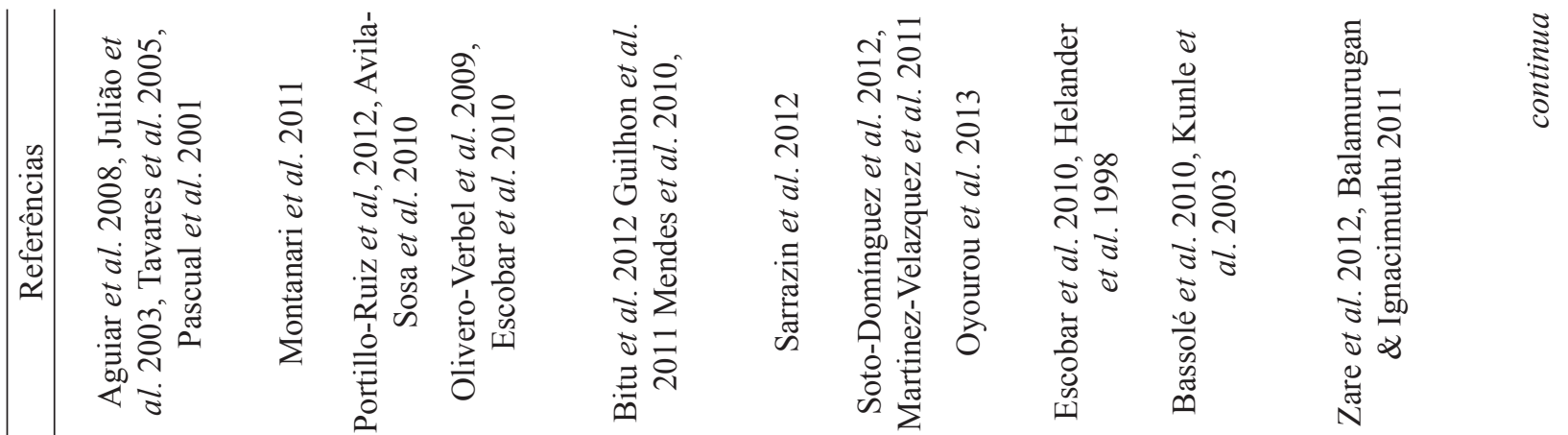

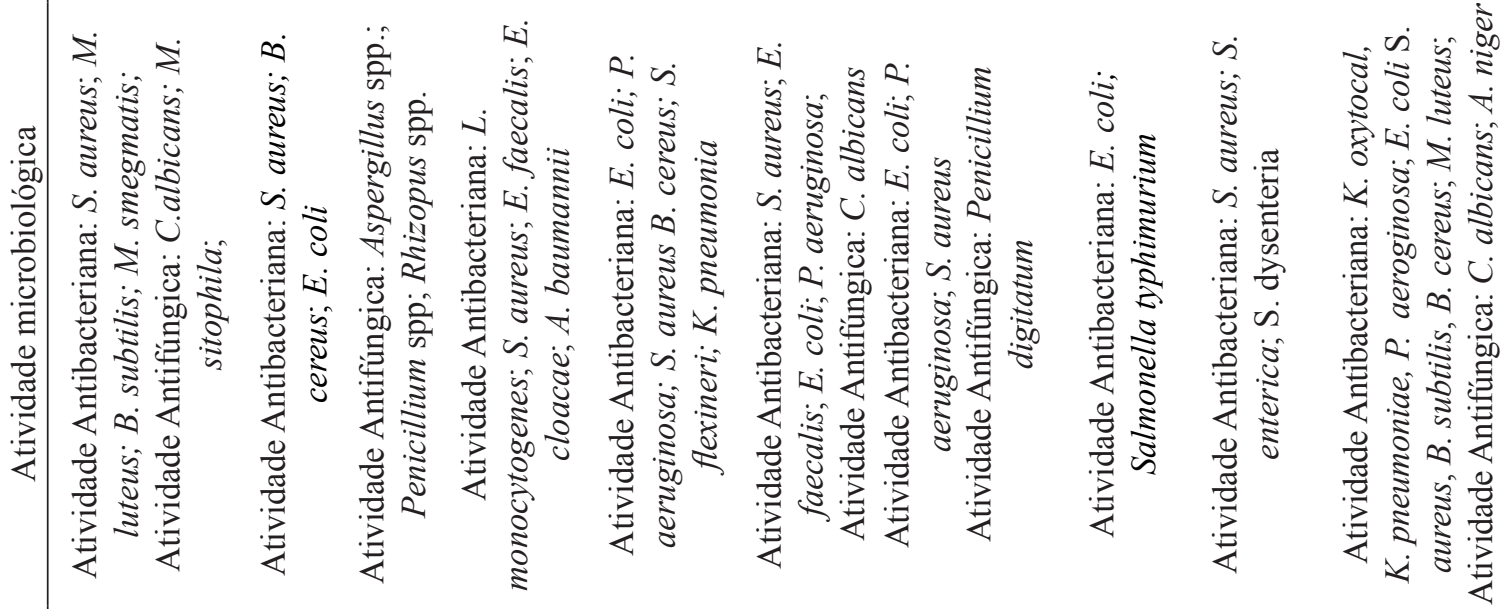

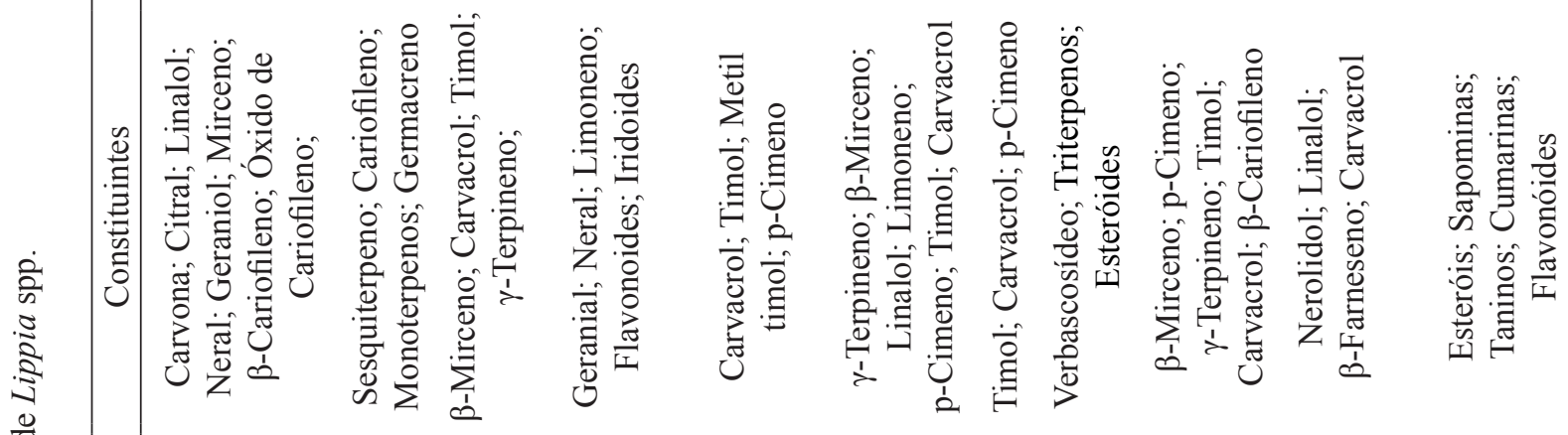
$\dot{\sum} \ll$ $\sum_{11}$ 空离 空

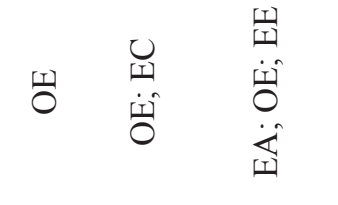
띵

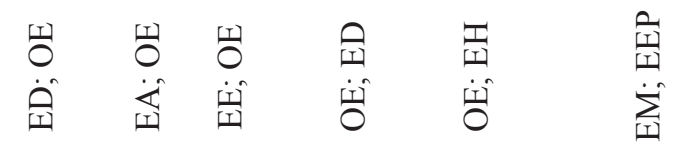
덩 « 苟 0
0
0
$\frac{0}{1}$
0
0
0
0
0
0
1

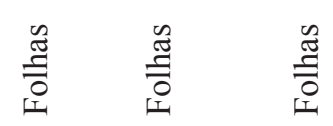

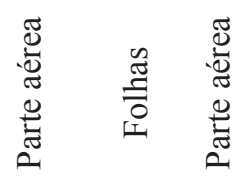

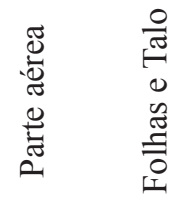
卷 


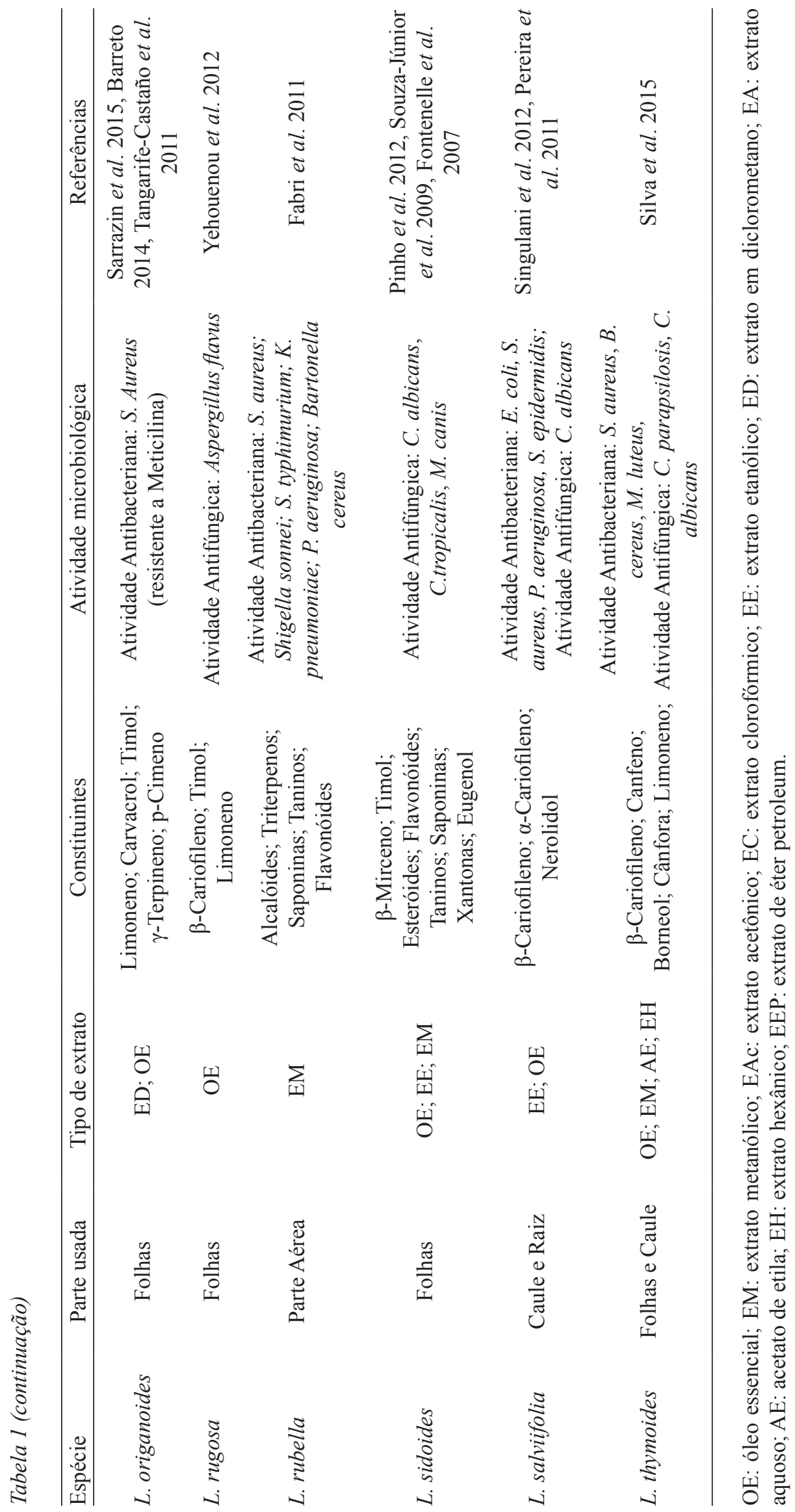


2012, Heldwein et al. 2012, Mamun-Or-Rashid et al. 2012, Neto et al. 2009, Aguiar et al. 2008, Sena Filho et al. 2006). Havendo referência também quanto ao uso de extrato aquoso de Lippia alba (Sena Filho et al. 2006).

Ensaios biológicos do óleo essencial do gênero Lippia mostraram atividade antimicrobiana mais eficaz contra bactérias gram-positivas (Staphylococcus aureus, Bacillus subtilis, Micrococcus flavus). Porém, suas espécies apresentam atividade também em gram-negativas (Escherichia coli, Pseudomonas aeruginosa, P. fluorescens, P. putida, Aeromonas hydrophila, Vibrio spp.) (Bandeira et al. 2014, Geromini et al. 2012, Mamun-Or-Rashid et al. 2012, Bitu et al. 2012, Gracia-Valenzuela et al. 2012, Correa-Royero et al. 2010, Fontenelle et al. 2007, Sena Filho et al. 2006) e são usualmente associadas à composição química de seus óleos e extratos, reportados em alguns trabalhos como ricas fontes de constituintes de natureza fenólica (López et al. 2011, Lemos et al. 1990), sendo apontadas como importantes recursos etnofarmacológicos para tratar doenças dermatológicas, respiratórias e gastrointestinais, bem como potencial sedativo, analgésico, antipirético, antihipertensivo e antiespasmódico (Batista et al. 2013, Melo et al. 2013, Geromini et al. 2012, Hennebelle et al. 2008a, Castro 2002, Salimena 2002, Pascual et al. 2001a).

Ao que se refere à atividade antifúngica das espécies de Lippia, a literatura apresenta, em sua grande maioria, ensaios fazendo uso de extratos das espécies L. alba e L. sidoides frente a Candida spp. e Microsporum canis dos gêneros Microsporum e Tricophyton (Oliveira et al. 2014, Geromini et al. 2012, Fontenelle et al. 2007), porém é possível encontrar em alguns estudos a ação de L. gracilis sobre fungos causadores de dermatoses (Fenner et al. 2006, Oliveira et al. 2006). Vale salientar que existem poucas pesquisas envolvendo a análise específica do potencial antifúngico dessas espécies e que, geralmente, estão atreladas às pesquisas bacterianas.

Os estudos com extratos e óleo essencial de Lippia spp., apontam esse gênero como fonte potencial para síntese de produtos fitoterápicos capazes de tratar infecções oportunistas ocasionadas por Candida albicans e outras espécies de Candida, encontradas ocasionalmente em aftas e corrimento vaginal e também Trichophytum rubrum e Trichophytum interdigitale, agentes causadores de dermatofitoses (Neri et al. 2007, Lorenzi \& Matos 2002), além de outros fungos fitopatogênicos como Monosporascus cannonballus (fitopatógeno de culturas de meloeiros). Dentre os fungos testados, os mais corriqueiros são filamentosos e leveduriformes (Araújo et al. 2014, Pozzatti et al. 2010, Silva et al. 2010, Oliveira et al. 2008).

Estudos fitoquímicos evidenciaram que essas atividades biológicas presentes principalmente em vegetais odoríferos, estão diretamente atreladas à composição química de seus óleos essenciais que trazem como constituintes majoritários desse gênero, o timol, carvacrol, carvona, limoneno, p-cimeno, geranial, linalol, neral, mirceno, $\gamma$-terpineno, $\beta$-mirceno, $\beta$-cariofileno e óxido de cariofileno (figura 1) (Soares \& Tavares-Dias 2013, Silva et al. 2006, Costa et al. 2005, Matos et al. 1996). É interessante ressaltar que esses constituintes majoritários podem sofrer alterações decorrentes da parte da planta utilizada para extração, do processo de extração e coleta, do ambiente e solo diferenciados (Bitu et al. 2012, Jannuzzi et al. 2011, Escobar et al. 2010, Nogueira et al. 2007, Zoghbi et al. 1998), além de outros fatores envolvidos.

\section{Estudos etnofarmacológicos e potencial antimicrobiano de espécies de Lippia}

\section{Lippia alba (Mill.) N.E. Br. ex Britton \& P. Wilson}

Popularmente conhecida como erva-cidreira brasileira (Bandeira et al. 2014) ou falsa melissa (Zétola et al. 2002), comumente relatada em estudos deste segmento como a mais conhecida e utilizada popularmente, devido a sua vasta aplicação medicinal, L. alba é uma planta de hábito arbustivo e possui grande variabilidade química. Segundo Heldwein et al. (2012) e Cunha et al. (2010), essa planta é comumente usada na medicina popular devido às suas diversas propriedades, grande parte delas comprovadas cientificamente, podendo apresentar efeito antihipertensivo, sedativo, reguladores de distúrbios estomacais e hepáticos, alívio de tosses, resfriados, dores de cabeça, bem como doenças causadas por fungos, bactérias e protozoários (Braga et al. 2005, Duarte et al. 2005, Pascual et al. 2001a, Vale et al. 1999). Carvalho e Fonseca (2005) encontraram no óleo essencial de $L$. alba uma concentração de $30-35 \%$ de carvona, composto que, segundo Neri e colaboradores (2007), é capaz de inibir o crescimento micelial dos fungos fitopatogênicos.

A literatura reporta diversos tipos de extratos desta espécie testados contra inúmeros microrganismos, 
<smiles>Cc1ccc(C(C)C)c(O)c1</smiles>

timol<smiles>CC(C)=CCCC(C)=CC=O</smiles>

geraniol

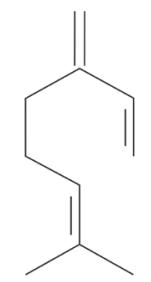

$\beta$ - mirceno

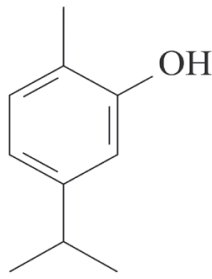

carvacrol

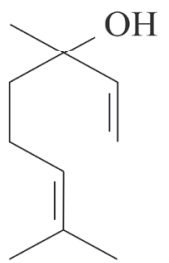

linalol

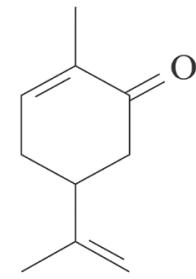

carvona

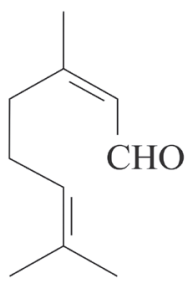

neral

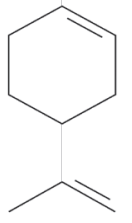

limoneno

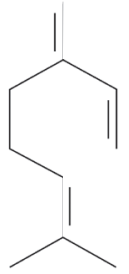

mirceno

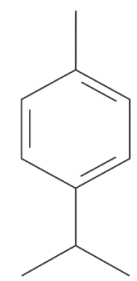

$p$ - cimeno

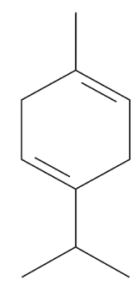

$\gamma$ - terpineno

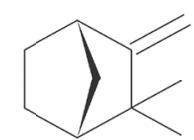

canfona

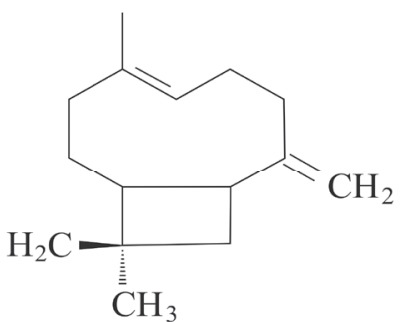

$\beta$ - cariofileno

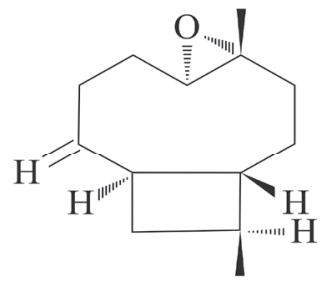

óxido de cariofileno

Figura 1. Estrutura química dos constituintes majoritários comumente encontrados em espécies do gênero Lippia.

entre eles encontra-se o trabalho de Aguiar et al. (2008), que investigaram, pelo método de difusão em disco de papel descrito por Bauer et al. (1996), a atividade antimicrobiana dos extratos hexânico, clorofórmico, acetônico, etanólico, metanólico e aquoso de raiz, caule e folhas, chegando à conclusão de que o extrato clorofórmico, acetônico e etanólico da raiz foram ativos frente a Staphylococcus aureus, Micrococcus luteus, Bacillus subtilis, Mycobacterium smegmatis, Candida albicans e Monilia sitophila e os extratos hexânico, etanólico e metanólico das folhas inibiram S. aureus, M. luteus, B. subtilis, M. smegmatis e M. sitophila.

Já Heinzmann e Barros (2007), mostraram para a fração butanólica e acetato de etila, provenientes do extrato etanólico de L. alba, atividade antiviral, contra o vírus Herpes simples tipo 1 resistente ao Aciclovir $^{\circledR} \mathrm{e}$ contra o vírus da pólio tipo 2, respectivamente. Devido a diversidade química encontrada nessa espécie, há alterações na sua atividade farmacológica fazendo com que essa planta seja classificada quimicamente de acordo com o seu principal constituinte, sendo três, os principais quimiotipos relatados no Brasil, o citral, carvona e linalol (Tavares et al. 2005, Vale et al. 1999). Quanto aos demais constituintes majoritários encontrados e isolados desta espécie, podemos citar o neral, geraniol, mirceno, $\beta$-cariofileno e óxido de cariofileno (figura 1) (Aguiar et al. 2008, Tavares et al. 2005, Julião et al. 2003, Pascual et al. 2001a).

\section{Lippia citriodora (Lam.) Kunth (Aloysia citriodora Palau)}

Lippia citriodora é uma espécie herbácea, conhecida em algumas regiões de Portugal como "limonete". Esta espécie pode ser naturalmente encontrada na América do Sul e bastante cultivada no Norte da África e Sudeste Europeu (Valentão et al. 2002). As suas folhas são relatadas em algumas literaturas como ricas em propriedades digestivas, antiespasmódica, antipirética e sedativas. Tem sido tradicionalmente utilizada em infusão para o tratamento de asma, febre, flatulência, cólicas, diarreia e indigestão (Newall et al. 1996). 
Alguns estudos sobre L. citriodora e a sua caracterização química, revelaram a presença de vários flavonóides e ácidos fenólicos, bem como sua propriedade antioxidante (Valentão et al. 2002, Valentão et al. 1999). Ao que diz respeito a sua atividade antimicrobiana, Bayoub et al. (2010), utilizando extrato etanólico das folhas desta espécie, realizaram um ensaio antimicrobiano, através do método de difusão em disco, frente a Listeria monocytogenes, Staphylococcus aureus, Enterococcus faecalis, Klebsiella pneumoniae, Enterobacter cloacae e Acinetobacter baumannii, onde obtiveram, como resultado, a inibição do crescimento $L$. monocytogenes, $S$. aureus, E. cloacae e A. baumannii. Já no trabalho de Correa-Royero et al. (2010), o óleo essencial de $L$. citriodora foi a amostra com o mais amplo espectro de atividade, mostrando-se ativo contra Candida krusei e Aspergillus fumigatus com MIC de 99,21 $\mu \mathrm{g} / \mathrm{mL}$ e $62,5 \mu \mathrm{g} / \mathrm{mL}$, respectivamente.

Para os contituintes majoritários nesta planta, Escobar et al. (2010) e Olivero-Verbel et al. (2009), encontraram geranial, neral, limoneno, flavonóides e Iridóides.

\section{Lippia grandis Schauer}

Esta espécie de arbusto, também chamada vulgarmente de "erva-do-marajó", estende-se pelo Nordeste do Brasil, podendo ser localizada em vegetações rasteiras no Oeste da Amazônia (Maia et al. 2003). O chá das suas folhas é administrado pela comunidade para tratar doenças hepáticas e estomacais (Maia et al. 2011), e as folhas frescas dessa planta são bastante utilizadas na culinária local (Serrazin et al. 2012).

Sarrazin et al. (2012) testaram o potencial antimicrobiano de L. grandis pelo método de difusão em disco contra 5 cepas bacterianas, sendo 2 grampositivas (Staphylococcus aureus e Enterococcus faecalis) e 3 gram-negativas (Escherichia coli, Klebsiella pneumoniae e Pseudomonas aeruginosa), e uma espécie fúngica (Candida albicans), revelando assim, atividade para todos os microrganismos testados, exceto para C. albicans e P. aeruginosa

Para a quantificação dos constituintes desse vegetal, ressalta-se a escassez de trabalhos, porém, o trabalho de Serrazin et al. (2012), relata a presença de $\gamma$-terpineno, $\beta$-mirceno, linalol, limoneno, $\mathrm{p}$-cimeno, timol e Carvacrol (figura 1).

\section{Lippia graveolens Kunth}

L. graveolens, conhecida como "orégano mexicano", é um arbusto de pequeno porte, encontrado no México e Sudeste da América do Norte, possui grande importância econômica e biológica, pois é reconhecida por possuir múltiplas propriedades medicinais, sendo amplamente usada na medicina tradicional e suas folhas, frescas ou secas, são apreciadas na elaboração de pratos culinários (Pascual et al., 2001a), no tratamento de doenças gastrointestinais, respiratórias, reumatismo, câncer e tumores (Hernandez et al. 2003).

Para averiguar a ação antimicrobiana do óleo essencial dessa espécie, Arana-Sanchez et al. (2010), utilizaram três quimiotipos dessa planta, o carvacrol, o timol e o p-cimeno. Os microrganismos testados foram Escherichia coli, Pseudomonas aeruginosa e Staphylococcus aureus. Os resultados mostraram que os OEs dos três quimiotipos são eficientes contra $S$. aureus e E. coli, não revelando atividade para $P$. aeruginosa, por possuir uma resistência maior a OEs contendo timol e carvacrol em sua composição (Hammer et al. 1999).

Quanto aos constituintes encontrados nessa espécie, se assemelham aos apontados anteriormente em outras espécies, sendo os principais, timol, carvacrol e p-cimeno (Soto-Domínguez et al. 2012, Martinez-Velazquez et al. 2011).

\section{Lippia javanica Spreng.}

A Lippia javanica ou "mato-limão", como é chamada em algumas regiões do continente sulafricano, é reportada como uma das espécies de Lippia mais utilizada por tribos indígenas da África do Sul. Esta planta possui hábito arbóreo com aproximadamente 2 $\mathrm{m}$ de altura, sendo extensivamente usada na medicina tradicional tanto por leigos quanto por curandeiros para tratar pequenos males (Pascual et al. 2001a).

Segundo análises de tratamento, um preventivo e outro curativo, realizado por Oyourou et al. (2013), em superfícies de laranjas expostas ao fungo Penicillium digitatum, o extrato etanólico de L. javanica mostrou-se efetivo para ambas situações, no entanto, sua eficácia foi maior no tratamento preventivo, quando foi aplicado uma concentração de $2,0 \mathrm{~g} \mathrm{~L}^{-1} \mathrm{de}$ extrato foliar sobre a casca de 10 laranjas e $1,0 \mathrm{~g} \mathrm{~L}^{-1} \mathrm{em}$ outras 10 , resultando em $90 \%$ de frutas não-doentes na maior concentração, com $80 \%$ das frutas limpas quando a concentração é reduzida a $1.0 \mathrm{~g} \mathrm{~L}^{-1}$.

Essa atividade é apontada, segundo o próprio autor, devido a presença do constituinte verbascosídeo, porém, também é apontado por ser um composto instável sob altas temperaturas. 
Lippia nodiflora (L.) Michx. (Phyla nodiflora (L.) Greene).

Lippia nodiflora é uma erva rasteira, perene, com pequenas flores brancas. Popularmente chamada de "erva-de-sapo", possui ampla distribuição no continente asiático e sul-africano. É usada tradicionalmente pelos povos locais e tribais do sul da Índia para o tratamento de bronquite, hipertensão e febre. Essa espécie é apontada por possuir propriedades diuréticas, antimaláricas, antiinflamatórias, analgésicas e antioxidantes (Kirthikar 1975).

A partir do extrato metanólico das folhas e flores de L. nodiflora, Zare et al. (2012), constataram a atividade antimicrobiana dessa espécie contra 4 bactérias gram-negativas (Kelebsiella oxytocal, $K$. pneumoniae, Pseudomonas aeroginosa e Escherichia coli), 4 gram-positivas (Staphylococcus aureus, Bacillus subtilis, B. cereus e Micrococcus luteus) e 2 fungos (Candida albicans e Aspergillus niger). A atividade observada pode ser atribuída a presença de terpenóides, sesquiterpenóides e ácido fenólico.

Outras investigações fitoquímicas feitas nesta espécie resultaram no isolamento de flavonóides, alcalóides, resina, açúcares, hispidulina, esteróis, saponinas, taninos e cumarinas (Zare et al. 2012, Balamurugan \& Ignacimuthu 2011, Bina et al. 2007).

\section{Lippia origanoides Kunth}

Lippia origanoides é uma planta comumente encontrada no Norte do Brasil, conhecida popularmente como "salva-do-marajó" e "alecrim-d'angola", é uma espécie de hábito arbustivo, cujas partes aéreas são usadas na culinária como aromatizante de pratos regionais, na medicina popular no tratamento de desordens gastrointestinais, doenças respiratórias, bem como anti-inflamatória e antisséptico oral (Sarrazin et al. 2015, Oliveira et al. 2007, Santos et al. 2004, Pascual et al. 2001a).

Diversos estudos têm verificado um significativo efeito inibitório do óleo essencial e extratos de L. origanoides, assim como os seus principais compostos isolados, testados contra variados micropatógenos de importância clínica, pelo método de difusão em discos de papel e Chequerboard (Tangarife-Castaño et al. 2011, Celis et al. 2007). Barreto et al. (2014) usando óleo essencial, realizaram bioensaios contra Staphylococcus aureus resistente a Meticilina (SARM), chegando a conclusão de que $L$. origanoides pode ser uma rica fonte de metabólitos secundários úteis na terapia contra doenças causadas por SARM, em sinergismo com antibióticos aminoglicosídicos.

Os principais compostos majoritários reportados para essa espécie são, segundo Sarrazin et al. (2015) e Tangarife-Castaño et al. (2011), timol, carvacrol, limoneno, $\gamma$-terpineno e p-Cimeno.

\section{Lippia sidoides Cham.}

Essa espécie é nativa do semiárido nordestino brasileiro, conhecida como "alecrim-pimenta" e possui hábito arbustivo. Seu óleo essencial possui grande valor comercial e farmacológico, devido aos constituintes encontrados nas folhas, com atividade inseticida, fungicida, bactericida, leishimanicida, larvicida, acaricida, anti-inflamatória e antiespasmódica (Carvalho et al. 2013, Lima et al. 2013, Farias-Junior et al. 2012, Veras et al. 2012, Cavalcanti et al. 2010, Fontenelle et al. 2007, Carvalho et al. 2003, Lorenzi \& Matos 2002, Lacoste et al. 1996, Lemos et al. 1990, Matos et al. 1989).

Por apresentar importantes propriedades, este vegetal faz parte do grupo de plantas selecionadas pelo Governo local como fitoterápico e é cultivado em hortos de plantas medicinais (Costa et al. 2002). Os resultados obtidos no estudo de Fontenelle et al. (2007), mostram que o óleo essencial de L. sidoides foi eficaz contra todas as cepas usadas para esse ensaio, sendo 4 cepas de Candida albicans com o MIC variando entre $620 \mathrm{mg} \mathrm{L}^{-1}$ e $1250 \mathrm{mg} \mathrm{L}^{-1}, 2$ cepas de Candida tropicalis com MIC de $1250 \mathrm{mg} \mathrm{L}^{-1}$ a 2.500 $\mathrm{mg} \mathrm{L}^{-1}$ e 6 cepas de Microsporum canis com MIC de $4 \mathrm{mg} \mathrm{L}^{-1}$ a $70 \mathrm{mg} \mathrm{L}^{-1}$.

Quanto aos compostos químicos encontrados nesta espécie, os mais mencionados são o $\beta$-mirceno, timol, catequinas, esteróides, flavonóides, taninos, saponinas, xantonas e eugenol (Pinho et al. 2012, Souza-Júnior et al. 2009, Fontenelle et al. 2007).

\section{Lippia thymoides Mart. \& Schauer}

Essa espécie arbustiva é popularmente conhecida como "alecrim-do-mato" ou "alecrim-do-campo" no Brasil, podendo chegar até dois metros de altura, ocorrendo na vegetação de Caatinga dos Estados da Bahia e de Minas Gerais. Ela é utilizada corriqueiramente em rituais religiosos e também na medicina popular para tratar feridas, febre, bronquite, reumatismo, dor de cabeça e fraqueza (Almeida \& Bandeira 2010, Funch et al. 2004).

Justificando o fato de haverem poucos estudos relatando científicamente a atividade biológica de 
L. thymoides, Silva et al. (2015), realizaram um estudo avaliando a bioatividade de extratos e frações in vitro e in vivo dessa espécie, indicando seu valor na medicina tradicional. A partir do extrato metanólico das folhas e galhos, os autores verificaram atividade antimicrobiana contra Staphylococcus aureus $(\mathrm{CIM}=$ $\left.0,69 \mathrm{mg} \mathrm{mL}^{-1}\right)$, Bacillus cereus $\left(\mathrm{CIM}=0,17 \mathrm{mg} \mathrm{mL}^{-1}\right)$, Candida parapsilosis $\left(\mathrm{CIM}=1,28 \mathrm{mg} \mathrm{mL}^{-1}\right)$, Micrococcus luteus $\left(\mathrm{CIM}=0,69 \mathrm{mg} \mathrm{mL}^{-1}\right)$, Candida albicans $(\mathrm{CIM}=2,48 \mathrm{mg} / \mathrm{mL})$, atividade antioxidante pelo método do b-Caroteno e de sequestro de DPPH, além da atividade antipirética, induzindo a redução da temperatura em ratos, administrando doses do extrato das folhas e galhos de L. thymoides.

No que compete a sua composição química, Silva (2015), aponta para a presença de $\beta$-cariofileno, canfeno, limoneno (figura 1), borneol e cânfora.

\section{Conclusão}

Os dados presentes na literatura e unidos nesta revisão, demonstram que o gênero Lippia é rico em espécies com diversas aplicabilidades medicinais. A partir de estudos dos seus diversos meios de preparação e seus diferentes extratos e óleos essenciais, constata-se que Lippia spp. apresenta propriedades biológicas que fazem desse gênero uma fonte natural para síntese de novos fitoterápicos.

Conforme mencionado anteriormente, devido à variabilidade específica atribuída ao gênero Lippia e seu uso popular, existem muitos testes e pesquisas intercalando seu potencial antimicrobiano e o desenvolvimento de fitoterápicos capazes de reduzir ou até mesmo transpor as resistências fúngicas e bacterianas através do uso combinado de produtos naturais com sintéticos já comercializados.

Em conclusão, esse levantamento apontou a relevância da família Verbenaceae através dos seus múltiplos compostos químicos, especialmente carvacrol, timol, citral, geraniol, sesquiterpenóides e terpenóides, que conferem ao gênero Lippia elevada atividade antibacteriana, antifúngica, antiviral, larvicida, antitumoral, antimalárica, dentre outras. Seu uso etnomedicinal confirma sua eficácia comprovada em inúmeros estudos assinalados nessa revisão. Contudo, acredita-se que o isolamento de novos princípios ativos a partir dessas espécies seria de grande importância científica, assim como a validação para seu uso popular, contribuindo assim, com o desenvolvimento de novos agentes fitoterápicos de qualidade e com o mínimo de efeitos colaterais possíveis frente ao tratamento de enfermidades.

\section{Agradecimentos}

Os autores agradecem ao programa de Mestrado em Recursos Naturais, da Universidade Estadual do Ceará, a Fundação Cearense de Apoio ao Desenvolvimento Científico e Tecnológico (FUNCAP) pelo suporte financeiro, ao Laboratório de Microbiologia e ao Herbário HUVA da Universidade Estadual Vale do Acaraú pelo apoio técnico.

\section{Literatura citada}

Aguiar, J.S., Costa, M.C.C.D., Nascimento, S.C., Sena, K.X.F.R. 2008. Atividade antimicrobiana de Lippia alba (Mill) N.E. Brown (Verbenaceae). Revista Brasileira Farmacognosia, pp. 436-440.

Albuquerque, C.C. 2013. Atividade antifúngica de alecrim-pimenta (Lippia sidoides Cham.) sobre Candida spp. Agropecuária Técnica, pp. 40-49.

Almeida, V.S. \& Bandeira, F.P.S.F. 2010. O significado cultural do uso de plantas da Caatinga pelos quilombolas do Raso da Catarina, município de Jeremoabo, Bahia, Brasil. Rodriguésia, pp. 195-209.

Arana-Sánchez, A., Estarrón-Espinosa, M., ObledoVázquez, E.N., Padilla-Camberos, E., Silva-Vázquez, R.E Lugo-Cervantes, E. 2010. Antimicrobial and antioxidant activities of Mexican oregano essential oils (Lippia graveolens $\mathrm{HBK}$ ) with different composition when microencapsulated in $\beta$-cyclodextrin. Letters in Applied Microbiology, pp. 585-590.

Araújo, J.C.L.V., Lima, E.O., Ceballos, B.S.O., B.S., Kristerson, R.D.L., Souza, E.L. \& Santos Filho, L. 2014. Ação antimicrobiana de óleos essenciais sobre microrganismos potencialmente causadores de infecções oportunistas. Revista de Patologia Tropical, pp. 55-64.

Atkins, S. 2004. Verbenaceae. In: J.W. Kadereit. The families and genera of fl owering plants. SpringerVerlag, Berlin, Germany. pp. 449-468.

Avila-Sosa, R., Gastélum-Franco, M.G., CamachoDávila, A., Torres-Muñoz, J.V., Nevárez-Moorillón, G.V. 2010. Extracts of Mexican oregano (Lippia berlandieri Schauer) with antioxidant and antimicrobial activity. Food and Bioprocess Technology, pp. 434-440.

Balamurugan, R.E., Ignacimuthu, S. 2011. Antidiabetic and Hypolipidemic effect of methanol extract of Lippia nodiflora $\mathrm{L}$. in streptozotocin induced diabetic rats. Asian Pacific Journal of Tropical Biomedicine, pp. 30-36.

Bandeira, M.G.L., Oliveira Filho, R.D., Souza Paiva, W., Abrantes, M.R., Silva, J.B.A. \& Damaceno, M.N. 2014. Perfil de sensibilidade de Staphylococcus spp. a frações protéicas extraídas de Erva Cidreira (Lippia alba (Mill.) N.E. Brown). Blucher Food Proceedings, pp. 163-167. 
Barbosa-Filho, J.M., Medeiros, K.C.P., Diniz, M.F.F.M., Batista, L.M., Athayde-Filho, P.F., Silva, M.S., Cunha, E.V.L., Almeida, J.R.G.S.E, QuintansJúnior, L.J. 2006. Natural products inhibitors of the enzyme acetylcholinesterase. Revista Brasileira de Farmacognosia, pp. 258-285.

Barreto, H.M., Lima, I.S., Coelho, K.M.R.N., Osório, L.R., Almeida Mourão, R., Santos, B.H.C. \& Lopes, J.A.D. 2014. Effect of Lippia origanoides H.B.K. essential oil in the resistance to aminoglycosides in methicillin resistant Staphylococcus aureus. European Journal of Integrative Medicine, pp. 560-564.

Bassolé, I.H.N., Lamien-Meda, A., Bayala, B., Tirogo, S., Franz, C., Novak, J.E. Dicko, M.H. 2010. Composition and antimicrobial activities of Lippia multiflora Moldenke, Mentha $\times$ piperita L. and Ocimum basilicum L. essential oils and their major monoterpene alcohols alone and in combination. Molecules, pp. 7825-7839.

Batista, R.S.A., Silva, G.S., Machado, S.E.F., Vieira, K.V.M. 2013. Atividade antifúngica de alecrimpimenta (Lippia sidoides Cham.) sobre Candida spp. Agropecuária Técnica. pp. 40-49.

Bauer, A.W., Kirby, W.M.M., Sherris, J.C., Turk, M. 1966. Antibiotic susceptibility testing by the standardized single disk method. American Journal Clinical Pathology, pp. 493-496.

Bayoub, K., Baibai, T., Mountassif, D., Retmane, A., \& Soukri, A. 2010. Antibacterial activities of the crude ethanol extracts of medicinal plants against Listeria monocytogenes and some other pathogenic strains. African Journal of Biotechnology, pp. 4251-4258.

Bina, S.S., Ahmad, F., Sattar, F.A. And Begum, S. 2007. Chemical constituents from the aerial parts of Lippia nodiflora Linn. Archives of Pharmacal Research, pp. 1507-1510.

Bitu, V., Botelho, M.A., Costa, J.G., Rodrigues, F.F., Veras, H.N., Martins, K.T. \& Siqueira, J.D.S. 2012. Phythochemical screening and antimicrobial activity of essential oil from Lippia gracillis. Brazilian Journal of Pharmacognosy, pp. 69-75.

Blank, A. F., Camêlo, L.C.A., Arrigoni-Blank, M.D.F., Pinheiro, J.B., Andrade, T.M., Niculau, E.D.S. \& Alves, P.B. 2015. Chemical Diversity in Lippia alba (Mill.) N.E. Brown Germplasm. The Scientific World Journal, pp. 11-15.

Bonzani, N.E., Filippa, E.M.E., Barboza, G.E. 1997. Particularidades epidérmicas en algunas especies de Verbenaceae. Anales del Instituto de Biologia, Universidad Nacional Autónoma de México, Serie Botánica, pp. 47-56.

Braga, M.E.M., Ehlert, A.D., Ming, L.C., Meireles, M.A.A. 2005. Supercritical fluid extraction from Lippia alba: global yields, kinetic data, and extract composition. The Journal of Supercritical Fluids, pp. 149-56.
Carvalho, C.C.C.R, Fonseca, M.M.R. 2005. Carvone: Why and how should one bother to produce this terpene. Food Chemistry, pp. 413-422.

Carvalho, A.F.U., Melo, V.M.M., Craveiro, A.A., Machado, M.I.L., Bantim, M.B., Rabelo, E.F. 2003. Larvicidal activity of the essential oil from Lippia sidoides Cham.against Aedes aegypti Linn. Memorias Instituto Oswaldo Cruz, pp. 569-571.

Carvalho, R.R.C., Laranjeira, D., Carvalho Filho, J.L.S., Souza, P.E., Blank, A.F., Alves, P.B., Jesus, H.C.R., Warwick, D.R.N. 2013. In vitro activity of essential oils of Lippia sidoides e Lippia gracilis and their major chemical components against Thielaviopsis paradoxa, causal agent of stem bleeding in coconut palms. Química Nova, pp. 241-244.

Cavalcanti, S.C.H., Niculau, E.S., Blank, A.F., Câmara, C.A.G., Araújo, I..N., Alves, P.B. 2010. Composition and acaricidal activity of Lippia sidoides essential oil against two-spotted spider mite (Tetranychus urticae Koch). Bioresourch Technology, pp. 829-832.

Castro, D.M., Ming, L.C., Marques M.O.M. 2002. Biomass producition and chemical composition of Lippia alba (Mill.) NE.Brown ex Britt e Wilson in leaves on different plant parts in different seasons. Acta Horticulturae, pp. 111-115.

Celis, C.N., Rivero, P.E., Isaza, J.H., Stashenko, E., Martínez, J.R. 2007. Estudio comparative de la composición y actividad biológica de los aceites esenciales extraídos de Lippia origanoides y Phyla dulcis, espécies de la família Verbenaceae. Scientiae et Technica, pp.103-105.

Compadre, C.M., Pezzuto, J.M., Kinghorn, A.D. \& Kamath, S.K. 1985. Hernandulcin: an intensely sweet compound discovered by review of ancient literature. Science, pp. 417-419.

Correa-Royero, J., Tangarife, V., Durán, C., Stashenko, E., \& Mesa-Arango, A. 2010. In vitro antifungal activity and cytotoxic effect of essential oils and extracts of medicinal and aromatic plants against Candida krusei and Aspergillus fumigatus. Revista Brasileira de Farmacognosia, pp. 734-741.

Costa, S.M.O., Lemos, T.L.G., Pessoa, O.D.L., Assunção, J.C.C. \& Braz-Filho, R. 2002. Constituintes químicos de Lippia sidoides (Cham.) Verbenaceae. Revista Brasileira de Farmacognosia, pp. 66-67.

Costa, J.G.M., Rodrigues, F.F.G., Angélico, E.C., Silva, M.R., Mota, M.L., Santos, N.K.A. \& Lemos, T.L.G. 2005. Estudo químico-biológico dos óleos essenciais de Hyptis martiusii, Lippia sidoides e Syzigium aromaticum frente às larvas do Aedes aegypti. Revista Brasileira de Farmacognosia, pp. 304-309.

Cunha, M.A., Barros, F.M.C., Oliveira Garcia, L., Lima Veeck, A.P., Heinzmann, B.M., Loro, V.L. \& Baldisserotto, B. 2010. Essential oil of Lippia alba: a new anesthetic for silver catfish, Rhamdia quelen. Aquaculture, pp. 403-406. 
Duarte, M.C.T., Figueira, G.M., Sartoratto, A., Rehder, V.L.G., Delarmelina, C. 2005. Anti-Candida activity of Brazilian medicinal plants. Journal of Ethnopharmacology, pp. 305-311.

Escobar, P., Leal, S.M., Herrera, L.V., Martinez, J.R., Stashenko, E. 2010. Chemical composition and antiprotozoal activities of Colombian Lippia spp. essential oils and their major components. Memórias do Instituto Oswaldo Cruz, pp. 184-190.

Fabri, R.L., Nogueira, M.S., Moreira, J.R., Bouzada, M.L.M., Scio, E. 2011. Identification of antioxidant and antimicrobial compounds of Lippia species by bioautography. Journal of Medicinal Food, pp. 840-846.

Fenner, R., Betti, A.H., Mentz, L.A., Rates, S.M.K. 2006. Plantas utilizadas na medicina popular brasileira com potencial atividade antifúngica. Revista Brasileira de Ciências Farmacêuticas, pp. 3-5.

Figueiredo, E.A.P., Ramos, H., Maciel, M.A.V., Vilar, M.D.C.M., Loureiro, N.G.E, Pereira, R.G. 2007. Pseudomonas aeruginosa: frequência de resistência a múltiplos fármacos e resistência cruzada entre antimicrobianos no Recife/PE. Revista Brasileira de Terapia Intensiva, pp. 421-427.

Fontenelle, R.O.S., Morais, S.M., Brito, E.H.S., Kerntopf, M.R., Brilhante, R.S.N., Cordeiro, R.A. \& Rocha, M.F.G. 2007. Chemical composition, toxicological aspects and antifungal activity of essential oil from Lippia sidoides Cham. Journal of Antimicrobial Chemotherapy, pp. 934-940.

Funch, L.S., Harley, R.M., Funch, R., Giulietti, A.M. \& Melo, E. 2004. Plantas Úteis da Chapada Diamantina, RiMa, São Carlos, Brazil, pp. 187.

Gracia-Valenzuela, M.H., Orozco-Medina, C. \& Molina-Maldonado, C. 2012. Efecto antibacteriano del aceite esencial de orégano (Lippia berlandieri) en bacterias patógenas de camarón Litopenaeus vannamei. Hidrobiológica, pp. 201-206.

Geromini, K.V.N., Roratto, F.B., Ferreira, F.G., Polido, P.P., Souza, S.G.H., Valle, J.S., Colauto, N.B., Linde, G.A. 2012. Atividade antimicrobiana de óleos essenciais de plantas medicinais. Arquivos de Ciências Veterinárias e Zoologia da UNIPAR, pp. 127-131.

Girón, L.M., Freire, V., Alonzo, A.Y, Cáceres, A. 1991. Ethnobotanical survey of the medicinal flora used by the Caribs of Guatemala. Journal of Ethnopharmacology, pp. 173-187.

Görnemann, T., Nayal, R., Pertz, H.H. \& Melzig, M.F. 2008. Antispasmodic activity of essential oil from Lippia dulcis Trev. Journal of Ethnopharmacology, pp. 166-169.

Gomes, S.V.F., Nogueira, P.C.L., Moraes, V.R.S. 2011. Aspectos químicos e biológicos do gênero Lippia enfatizando Lippia gracilis Schauer. Eclética Química, pp. 64-77.
Goulart, S.L. \& Marcati, C.R. 2008. Anatomia comparada do lenho em raiz e caule de Lippia salviifolia Cham. (Verbenaceae). Revista Brasileira de Botânica, pp. 263-275.

Guilhon, C.C., Raymundo, L.J.R.P., Alviano, D.S., Blank, A.F., Arrigoni-Blank, M.F., Matheus, M.E., Cavalcanti, S.C.H. \& Alviano, C.S. 2011. Characterisation of the anti-inflammatory and antinociceptive activities and the mechanism of the action of Lippia gracilis essential oil. Journal of Ethnopharmacology, pp. 406-413.

Guimarães, L.G.L., Cardoso, M.G., Souza, R.M., Zacaroni, M.B. \& Santos, G.R. 2014. Óleo essencial de Lippia sidoides nativas de Minas Gerais: composição, estruturas secretoras e atividade antibacteriana. Revista Ciência Agronômica, pp. 267-275.

Hammer, K.A., Carson, C.F. \& Riley, T.V. 1999. Antimicrobial activity of essential oils and other plant extracts. Journal of Applied Microbiology, pp. 985-990.

Helander, I.M., Alakomi, H.L., Latva-Kala, K., MattilaSandholm, T., Pol, I., Smid, E.J. \& Von Wright, A. 1998. Characterization of the action of selected essential oil components on Gram-negative bacteria. Journal of Agricultural and Food Chemistry, pp. 3590-3595.

Heinzmann, B.M. \& Barros, F.M.C. 2007. Potencial das Plantas Nativas Brasileiras para o desenvolvimento de Fitomedicamentos tendo como exemplo Lippia alba (Mill.) N.E. Brown (Verbenaceae). Saúde, Santa Maria, pp. 43-48.

Heldwein, C.G., Silva, L.L., Reckziegel, P., Barros, F.M.C., Bürer, M.E., Baldisserotto, B., Mallmann, C.A., Schmidt, D., Caron, B.O. \& Heinzmann, B.M. 2012. Participation of the GABAergic system in the anesthetic effect of Lippia alba (Mill.) N.E. Brown essential oil. Brazilian Journal of Medical and Biological Research, pp. 436-443.

Hennebelle, T., Sahpaz, S., Joseph, H.E. Bailleul, F. 2008a. Ethnopharmacology of Lippia alba. Journal of Ethnopharmacology, pp. 211-222.

Hernández, T., Canales, M., Avila, J. G., Duran, A., Caballero, J., Romo De Vivar, A., Lira, R. 2003. Plantas de uso medicinal en Guatemala, Journal of Ethnopharmacology, pp. 181.

Jannuzzi, H., Mattos, J.K.A., Vieira, R.F., Silva, D.B., Bizzo, H.R., Gracindo, L.A.M. 2010. Avaliação agronômica e identificação de quimiotipos de erva cidreira (Lippia alba) no Distrito Federal. Horticultura Brasileira, pp. 412-417.

Julião, L.S., Tavares, E.S., Lage, C.L.S.E, Leitão, S.G. 2003. Cromatografia em camada fina de extratos de três quimiotipos de Lippia alba (Mill.) N.E. Br. (erva-cidreira). Revista Brasileira de Farmacognosia, pp. 36-38. 
Kirthikar, K.R. \& Basu, B.D. 1975. Indian Medicinal Plants. Dehradun, Bishen Mahendra Pal Singh, pp. 1915-1917.

Kunle, O., Okogun, J., Egamana, E, Emojevwe, E., Shok, M. 2003. Antimicrobial activity of various extracts and carvacrol from Lippia multiflora leaf extract. Phytomedicine, pp. 59-61.

Lacoste, E., Chaumont, J.P., Mandin, D., Plumel, M.M. \& Matos, F.J. 1996. Antiseptic properties of essential oil of Lippia sidoides Cham.: application to the cutaneous microflora. Annales Pharmaceutiques Françaises, pp. 228-30.

Lemos, T.L.G., Matos, F.J.A., Alencar, J.W., Craveiro, A.A., Clarck, A.M. \& McChesney, J.D. 1990. Antimicrobial activity of Esential Oils of Brazilian Plants. Phytotherapy Research., pp. 82-84.

Lima, J.K.A., Albuquerque, E.L.D., Santos, A.C.C., Oliveira, A.P., Araújo, A.P.A., Blank, A.F., ArrigoniBlank, M.F., Alves, P.B., Santos, D.A., Bacci, L. 2013. Biotoxicity of some plant essential oils against the termite Nasutitermes corniger (Isoptera:Termitidae). Industrial Crops Products, pp. 246-251.

López, M.A., Stashenko, E.E.E. Fuentes, J.L. 2011. Chemical composition and antigenotoxic properties of Lippia alba essential oils. Genetics and Molecular Biology, pp. 479-488.

Lorenzi, H.E., Matos, F.J.A. 2002. Plantas medicinais no Brasil: nativas e exóticas. Nova Odessa. Instituto Pantarump, pp. 494-495.

Machado, T.F., Nogueira, N.A.P, Pereira, R.C.A., Sousa, C.T. \& Batista, V.C.V. 2014. The antimicrobial efficacy of Lippia alba essential oil and its interaction with food ingredientes. Brazilian Journal of Microbiology, pp. 699-705.

Machado, T.F., Borges, M.F., Bruno, L.M. 2011. Aplicação de Antimicrobianos Naturais na Conservação de Alimentos. Empresa Brasileira de Pesquisa Agropecuária. Ministério da Agricultura, Pecuária e Abastecimento, pp. 21-27

Maciel, M.A.M., Pinto, A.C., Veiga Jr., V.F., Grynberg, N.F. \& Echevarria, A. 2002. Plantas medicinais: a necessidade de estudos multidisciplinares. Química Nova, pp. 429-438.

Maia, J.G.S., Taveira, F.S.N., Andrade, E.H.A., Silva, M.H.L. \& Zoghbi, M.G.B. 2003. Essential oils of Lippia grandis Schau. Flavour Fragrance Journal, pp. 417-420.

Mamun-Or-Rashid, A.N.M., Islam, R.E \& Dash, B.K. 2012. In vitro Antibacterial effect of bushy matgrass (Lippia alba Mill.) extracts. Research Journal of Medicinal Plants, pp. 334-340.

Matos, F.J.A. 1989. Plantas medicinais: guia de seleção e emprego de plantas usadas em fitoterapia no nordeste do Brasil. Fortaleza: Universidade Federal do Ceará, pp. $344-348$
Matos, F.J.A., Machado, M.I.L., Craveiro, A.A., Alencar, J.W.E. Silva, M.G.V. 1999. Medicinal Plants Northeast of Brazil containing Tymol e Carvacrol- Lippia sidoides Cham. and Lippia gracilis H.B.K. (Verbenaceae). Journal Essential Oil Research. Wheaton, pp. 666-668.

Melo, J.O., Bitencourt, T.A., Fachin, A.L., Cruz, E.M.O., Jesus, H.C.R, Alves, P.B. \& Arrigoni-Blank, M.F. 2013. Antidermatophytic and antileishmanial activities of essential oils from Lippia gracilis Schauer genotypes. Acta Tropica, pp. 110-115.

Mendes, S.S., Bomfim, R.R., Jesus, H.C.R., Alves, P. B., Blank, A.F., Estevam, C.S. E. \& Thomazzi, S. M. 2010. Evaluation of the analgesic and antiinflammatory effects of the essential oil of Lippia gracilis leaves. Journal of Ethnopharmacology, pp. 391-397.

Metan, G., Zarakolu, P., Unal, S. 2005. Rapid detection of antibacterial resistance in emerging Gram-positive cocci. Hospitalar Infection Review, pp. 9-93.

Montanari, R.M., Barbosa, L.C.A., Demuner, A.J., Silva, C.J., Carvalho, L.S.E \& Andrade, N.J. 2011. Chemical composition and antibacterial activity of essential oils from verbenaceae species: alternative sources of $(E)$-caryophyllene and germacrene-D. Química Nova, pp. 9-11.

Nascimento, P.F.C., Nascimento, A.C., Rodrigues, C.S., Antoniolli, A.R., Santos, P.O., Barbosa Júnior, A.M. \& Trindade, R.C. 2007. Atividade antimicrobiana dos óleos essenciais: uma abordagem multifatorial dos métodos. Revista Brasileira de Farmacognosia, pp. 108-113.

Neri, F., Mari, M., Brigati, S.E Bertolini, P. 2007. Fungicidal activity of plant volatile compounds for controlling Monilinia laxa is stone fruit. Plant Disease. Saint Paul, pp. 30-35.

Neto, A.C., Netto, J.C., Pereira, P.S., Pereira, A., TalebContini, S.H., Franca, S.C.E. \& Beleboni, R.O. 2009. The role of polar phytocomplexes on anticonvulsant effects of leaf extracts of Lippia alba (Mill.) NE Brown chemotypes. Journal of Pharmacy and Pharmacology, pp. 933-939.

Newall, C.A., Anderson, L.A. \& Phillipson, J.D. 1996. Herbal Medicines-A Guide for Health-care Professionals. The Pharmaceutical Press, pp. 179-189.

Nogueira, M.A., Diaz, G. \& Sakumo, L. 2007. Caracterização química e atividade biológica do óleo essencial de Lippia alba cultivada no Paraná. Revista de Ciências Farmacêuticas Básica e Aplicada, pp. 273-278.

O'Leary, N., Múlgura, M.E. \& Morrone, O. 2007. Revisión taxonómica de las especies del género Verbena (Verbenaceae): serie Pachystachyae, Annals Missouri Botanical Garden, pp. 571-621.

Oliveira, G.T., Ferreira, J.M.S., Rosa, L.H., Siqueira, E.P., Johann, S. \& Lima, L.A.R.S. 2014. In vitro antifungal activities of leaf extracts of Lippia alba (Verbenaceae) against clinically important yeast species. Revista da Sociedade Brasileira de Medicina Tropical, pp. 247-250. 
Oliveira, O.R., Terao, D., Carvalho, A.C.P.P., Innecco, R. \& Albuquerque, C.C. 2008. Efeito de óleos essenciais de plantas do gênero Lippia sobre fungos contaminantes encontrados na micropropagação de plantas. Revista Ciência Agronômica, Fortaleza, pp. 94-100.

Oliveira, D.R., Leitão, G.G. Santos, S.S., Bizzo, H.R., Lopes, D., Alviano, C.S., Alviano, D.S. \& Leitão, S.G. 2006. Ethnopharmacological study of two Lippia species from Oriximiná, Brazil. Journal of Ethnopharmacology, pp. 103-108.

Oliveira, D.R., Leitão, G.G., Bizzo, H.R., Lopes, D., Alviano, D.S., Alviano, C.S. \& Leitão, S.G. 2007. Chemical and antimicrobial analyses of essential oil of Lippia origanoides H.B.K. Food Chemistry, pp. 236-240.

Oliveira, F.P., Lima, E.O., Siqueira Júnior, J.P., Souza, E.L., Santos, B.H.C. \& Barreto, H.M. 2006. Effectiveness of Lippia sidoides Cham. (Verbenaceae) essential oil in inhibiting the growth of Staphylococcus aureus strains isolated from clinical material. Revista Brasileira de Farmacognosia, pp. 510-516.

Olivero-Verbel, J., Güette-Fernandez, J., Stashenko, E. 2009. Acute toxicity against Artemia franciscana of essential oils isolated from plants of the genus Lippia and Piper collected in Colombia. Boletin Latinoamericano y del Caribe de Plantas Medicinales y Aromáticas, pp. 419-427.

Oyourou, J.N., Combrinck, S., Regnier, T.E., Marston, A. 2013. Purification, stability and antifungal activity of verbascoside from Lippia javanica and Lantana camara leaf extracts. Industrial Crops and Products, pp. 820-826.

Pascual, M.E., Slowing, K., Carretero, E., Mata, D.S., Villar, A. 2001a. Lippia: traditional uses, chemistry and pharmacology: a review. Journal of Ethnopharmacology, pp. 201-214.

Pascual, M.E., Slowing, K., Carretero, E., Mata, D.S., Villar, A. 2001b. Antiulcerogenic activity of Lippia alba (Mill.) N.E. Brown (Verbenaceae). Il Farmaco. pp. 501-504.

Pereira, A.M.S., Franca, S.C., Fachin, A.L., Bertoni, B.W., Pina, E.S. \& Coppede, J.S. 2011. Phytotherapic pharmaceutical combination of Lippia salviifolia and Lippia sidoides, phytotherapic pharmaceutical composition, process for preparing a phytotherapic pharmaceutical composition and veterinary uses thereof. U.S. Patent Application, pp. 814-820.

Pereira, A.D.A., Cardoso, M.D.G., Abreu, L.R.D., Morais, A.R.D., Guimarães, L.G.D.L.E. \& Salgado, A.P.S.P. 2008. Caracterização química e efeito inibitório de óleos essenciais sobre o crescimento de Staphylococcus aureus e Escherichia coli. Ciência e Agrotecnologia, pp. 887-893.

Pérez, S., Meckes, M., Pérez, C., Susunaga, A.E. \& Zavala, M. A. 2005. Anti-inflammatory activity of Lippia dulcis. Journal of Ethnopharmacology, pp. 1-4.
Pessoa, O.D.L., Carvalho, C.M.B., Silvestre, J.O.V.L., Lima, M.C.L., Neto, R.M., Matos, F.J.A. \& Lemos, T.L.J. 2005. Antibacterial activity of the essential oil from Lippia aff. gracilis. Fitoterapia, pp. 711-714.

Pinho, L., Souza, P. N. S., Sobrinho, E. M., Almeida, A. C. E \& Martins, E. R. 2012. Atividade antimicrobiana de extratos hidroalcoólico das folhas de alecrimpimenta, aroeira, barbatimão, erva baleeira e do farelo da casca de pequi. Ciência Rural, pp. 326-331.

Pinto, E.P.P., Amorozo, M.C.M., Furlan, A. 2006. Conhecimento popular sobre plantas medicinais em comunidades rurais de mata atlântica - Itacaré, BA, Brasil. Acta Botanica Brasilica, pp. 751-762.

Portillo-Ruiz, M.C., Sánchez A.S., Ramos, S.V., Muñoz, J.V.T., Nevárez-Moorillón. 2012. Antifungal effect of Mexican oregano (Lippia berlandieri Schauer) essential oil on a wheat flour-based medium. Journal of Food Science, pp. 441-445.

Pozzatti, P., Loreto, E.S., Lopes, P.G.M., Athayde, M. L., Santurio, J.M.E \& Alves, S.H. 2010. Comparison of the susceptibilities of clinical isolates of Candida albicans and Candida dubliniensis to essential oils. Mycoses, pp. 12-15.

Reis, A.C., Sousa, S.M., Vale, A.A., Pierre, P.M.O., Franco, A.L., Campos, J.M.S., Vieira, R.F. \& Viccini, L.F. 2014. Lippia alba (Verbenaceae): A New Tropical Autopolyploid Complex. American Journal of Botany, pp. 1002-1012.

Salimena, F.R.G.E \& Múlgura, M.E. 2015. Notas taxonômicas em Verbenaceae do Brasil. Rodriguésia, pp. 191-197.

Salimena, F.R.G. 2002. Novos sinônimos e tipificacão em Lippia sect. Rhodolippia (Verbenaceae), Darwiniana, pp. 121-125.

Santos, F.J.B., Lopes, J.A.D., Cito, A.M.G.L., Oliveira, E.H., Lima, S.G. \& Reis, F. A. M. 2004. Composition and biological activity of essential oil from Lippia origanoides HBK. Journal of Essential Oil Research, pp. 504-506.

Santos, J.D.F.L., Pagani, E., Ramos, J.E. \& Rodrigues, E. 2012. Observations on the therapeutic practices of riverine communities of the Unini River, AM, Brazil. Journal of Ethnopharmacology, pp. 503-515.

Santos, A., Nunes, T., Coutinho, T.E. \& Silva, M. 2015. Uso popular de espécies medicinais da família Verbenaceae no Brasil. Revista Brasileira de Plantas Medicinais, pp. 980-991.

Sena Filho, J. G., Melo, J. G. S., Saraiva, A. M. et al. 2006. Antimicrobial activity and phytochemical profi le from the roots of Lippia alba (Mill.) N.E. Brown. Revista Brasileira de Farmacognosia, pp. 506-509.

Serrazin, S. L. F., Oliveira, R. B., Barata, L. E. S., Mourão, R. H. V. 2012. Chemical composition and antimicrobial activity of the essential oil of Lippia grandis Schauer (Verbenaceae) from the western. Amazon. Food Chemistry, pp. 1474-1478. 
Sarrazin, S. L. F., Silva, L. A., Assunção, A. P. F., Oliveira, R. B. F. et al. 2015. Antimicrobial and Seasonal Evaluation of the Carvacrol-Chemotype Oil from Lippia origanoides Kunth. Journal Molecules. pp. 1860-1871.

Silva, F.S., Menezes, P.M.N., Souza, P.G.S., Oliveira, A.L.S., Souza, E.A.A., Bamberg, V.M., Oliveira, H.R., 1 Sheilla Andrade de Oliveira,4 Roni Evêncio e Araújo,4 Ana Paula Trovatti Uetanabaro,5 Tânia Regina dos Santos Silva,6 Jackson Roberto Guedes da Silva Almeida, 1,2,7 and Angélica Maria Lucchese2,3 Pharmacological Basis for Traditional Use of the Lippia thymoides.Evidence-Based Complementary and Alternative Medicine, pp. 1-10.

Silva, N. A., Oliveira, F. F., Costa, L. C. B., Bizzo, H. R., Oliveira, R. A. 2006. Caracterização química do óleo essencial da erva cidreira (Lippia alba (Mill.) N. E. Br.) cultivada em Ilhéus na Bahia. Revista Brasileira de Plantas Medicinais, p. 52-55.

Silva, M. I. G., Gondim, A. P. S., Nunes, I. F. S., E Sousa, F. C. F. 2006. Utilização de fitoterápicos nas unidades básicas de atenção à saúde da família no município de Maracanaú (CE). Revista Brasileira de Farmacognosia, pp. 455-62.

Silva, K. J. P., Cordeito, A. G., Nogueira, D. R. S., Sales Junior, R. 2010. Monosporascus cannonballus: Agente causal do colapso ou morte súbita do meloeiro. Revista Verde, Mossoró, p. 11-18.

Singulani, J.L., Silva, P.S, Raposo, N.R.B, Siqueira, E.P., Zani, C.L., Alves, T.M.A. \& Viccini, L.F. 2012. Chemical composition and antioxidant activity of Lippia species. Journal of Medicinal Plants Research. pp. 4416-4422.

Soares, B. V. \& Tavares-Dias, M. 2013. Espécies de Lippia (Verbenaceae), seu potencial bioativo e importância na medicina veterinária e aquicultura. Biota Amazônia. pp. 109-123.

Soto-Domínguez, A., García-Garza, R., RamírezCasas, Y., Morán-Martínez, J. \& Serrano-Gallardo, L.B. 2012. El Extracto Acuoso de Orégano (Lippia graveolens HBK) del Norte de México Tiene Actividad Antioxidante sin mostrar un Efecto Tóxico in vitro e in vivo. International Journal of Morphology, pp. 937-944.

Souto-Bachiller, F.A., De Jesus-Echevarría, M., Cárdenas-González, O.E., Acuña-Rodriguez, M. F., Meléndez, P.A.E, Romero-Ramsey, L. 1997. Terpenoid composition of Lippia dulcis. Phytochemistry, pp. 1077-1086.

Souza Junior, I.T., Sales, N.L.P. \& Martins, E.R. 2009. Efeito fungitóxico de óleos essenciais sobre Colletotrichum gloeosporioides, isolado do maracujazeiro amarelo. Biotemas, pp. 77-83,

Souza, V.C. \& Lorenzi, H. 2012. Botânica Sistemática: guia ilustrado para identificação das famílias nativas e exóticas no Brasil, baseado em APG III. Instituto Plantarum, pp. 674-678.
Tangarife-Castaño, V., Correa-Royero, J., ZapataLondônio, B., Duran, C., Stanshenko, E., MesaErango, A.C. 2011. Anti-Candida albicans activity, cytotoxicity and interaction with antifungal drugs of essential oils and extracts from aromatic and medicinal plants. Infectio, p. 160-167.

Tavares, E.S., Julião, L.S., Lopes, D., Bizzo, H.R., Lage, C.L.S. \& Leitão, S.G. 2005. Análise do óleo essencial de folhas de três quimiotipos de Lippia alba (Mill.) N. E. Br. (Verbenaceae) cultivados em condições semelhantes. Revista Brasileira de Farmacognosia, pp. 1-5.

Tatsadjieu, N.L., Dongmo, P.J., Ngassoum, M.B., Etoa, F.X. \& Mbofung, C.M.F. 2009. Investigations on the essential oil of Lippia rugosa from Cameroon for its potential use as antifungal agent against Aspergillus flavus Link ex. Fries. Food Control, pp. 161-166.

Vale, T.G., Matos, F.J., Lima, T.C., Viana, G.S. 1999. Behavioral effects of essential oils from Lippia alba (Mill.) N.E. Brown chemotypes. Journal of Ethnopharmacology, pp. 127-133.

Valentão, P., Fernades, E., Carvalho, F., Andrade, P.B., Seabra, R.M. \& Basto, M.L. 2002. Studies on the antioxidant activity of Lippia citriodora infusion: scavenging effect on superoxide radical, hydroxyl radical and hypochlorous acid. Biological and Pharmaceutical Bulletin, pp. 1324-1327.

Valentão, P., Andrade, P.B., Areias, F., Ferreres, F. \& Seabra, R.M. 1999. Analysis of vervain flavonoids by HPLC/diode array detector method. Its application to quality control. Journal of Agricultural and Food Chemistry, pp. 4579-4582.

Yehouenou, B., Ahoussi, E., Sessou, P., Alitonou, G.A., Toukourou, F. \& Sohounhloue, D. 2012. Chemical composition and antimicrobial activities of essential oils (EO) extracted from leaves of Lippia rugosa A. Chev against foods pathogenic and adulterated microorganisms. African Journal of Microbiology Research, pp. 5496-5505.

Zare, Z., Majd, A., Sattari, T. N., Iranbakhsh, A., Mehrabian, S. 2012. Antimicrobial activity of leaf and flower extracts of Lippia nodiflora L. (Verbenacea). Journal of Plant Protection Research, pp. 401-403.

Zétola, M., Lima, T.C.M., Sonaglio, D., González-Ortega, G., Limberger, R.P, Petrovick, P.R. \& Bassani, V.L. 2002. CNS activities of liquid and spray-dried extracts from Lippia alba - Verbenaceae (Brazilian false melissa). Journal of Ethnopharmacology, pp. 207-215.

Zoghbi, M.G.B., Andrade, E.H.A., Santos, A.S., Silva, M.H.L., Maia, J.G.S. 1998. Essential Oils of Lippia alba (Mill.) N.E. Br Growing Wild in the Brazilian Amazon. Flavour and Fragrance Journal, pp. 47-48. 